Special Issue of the 7th International Advances in Applied Physics and Materials Science (APMAS 2017)

\title{
Welding Time Effect on Nugget Sizes in Resistance Spot Welding of SPA-C Steel Sheets used in Railway Vehicles
}

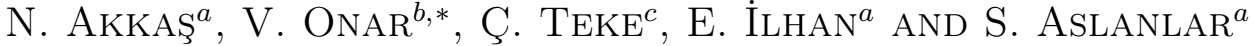 \\ ${ }^{a}$ Faculty of Technology, Sakarya University, Sakarya, Turkey \\ ${ }^{b}$ Faculty of Technology, Pamukkale University, Denizli, Turkey \\ ${ }^{c}$ Institute of Natural Sciences, Sakarya University, Sakarya, Turkey
}

\begin{abstract}
This paper presents an experimental study on resistance spot welding of SPA-C steel sheets used in side wall and roof in rail vehicles. SPA-C steel sheets having $2.3 \mathrm{~mm}$ thickness were joined by using resistance spot welding as lap joint. A timer and current controlled resistance spot welding machine having $120 \mathrm{kVA}$ capacity and a pneumatic application mechanism with a single lever was used to prepare the specimens. Welding periods were chosen as $10,15,20,25$, and 30 cycles and also welding currents were increased from $6 \mathrm{kA}$ up to $14 \mathrm{kA}$ by rise of $0.5 \mathrm{kA}$. The electrode force was kept constant at $6 \mathrm{kN}$. The nugget sizes of prepared welding specimens were calculated by means of an optical microscope and the obtained results were supported by diagrams and, finally, appropriate welding parameters were advised to the users.
\end{abstract}

DOI: 10.12693/APhysPolA.134.235

PACS/topics: resistance spot welding, atmospheric corrosion resistant steels, rail vehicles

\section{Introduction}

Resistance spot welding (RSW) is a joining process in which coalescence of the metal sheets is produced at the faying surface by the heat generated at the joint by the resistance of the work to the flow of electric current [1]. Because of the processes requires relatively simple equipment; it is easily and normally automated and once the welding parameters established it should be possible to produce repeatable welds, the resistance spot welding is the most widely used joining process for sheet materials [2].

Resistance spot welding is the most widely common method used for joining structures and plates of different materials in automobile, railroad, airplane structures, and in certain nonstructural components in aerospace industry [3].

Like any other welding processes, the quality of the joint in RSW is directly influenced by welding input parameters. In most cases, good spot-welding practice requires three parameters that have to be controlled, namely, current, time, and electrode force [3].

Welding time is directly proportional to the amount of heat being generated. Increased welding time results in increased heat generation. It facilitates nugget growth which enhances the mechanical performance of weldments. However, excessive welding time results in expulsion due to nugget overgrowth. This can introduce weld defects into the weldment, such as voids and excessive indentation, which adversely affects weld performance [4].

The purpose of this work was to investigate the effect of welding time on the resistance spot weld quality of

*corresponding author; e-mail: vonar@pau.edu.tr atmospheric corrosion resistant steels such as: surface appearances, nugget diameter, nugget height, nugget size ratio. The macrostructure of the welded samples was evaluated.

\section{Experimental studies}

The materials studied are SPA-C weathering steel sheets having a $2.3 \mathrm{~mm}$ thickness, and which are used in side wall and roof application of rail vehicle bodies. The chemical composition and the mechanical properties of the sheet are, respectively, shown in Table I and Table II.

Chemical composition of steel sheets

TABLE I used in experiments (wt\%).

\begin{tabular}{c|c|c|c|c}
\hline \hline $\mathrm{C}$ & $\mathrm{Si}$ & $\mathrm{Mn}$ & $\mathrm{P}$ & $\mathrm{S}$ \\
\hline 0.099 & 0.397 & 0.433 & 0.091 & 0.001 \\
\hline \hline $\mathrm{Mo}$ & $\mathrm{Al}$ & $\mathrm{Cu}$ & $\mathrm{Cr}$ & $\mathrm{Ni}$ \\
\hline 0.006 & 0.045 & 0.331 & 0.605 & 0.257
\end{tabular}

Mechanical properties of the sheet steel.

TABLE II

\begin{tabular}{l|c} 
yield strength [MPa] & 430 \\
tensile strength [MPa] & 550 \\
total elongation [\%] & 45
\end{tabular}

A timer and current controlled RSW machine having $120 \mathrm{kVA}$ capacity and pneumatic application mechanism with a single lever were used in the experiments.

Welding was carried out by using water cooled conical $\mathrm{Cu}-\mathrm{Cr}$ electrodes having a contact surface of the same diameter $(7 \mathrm{~mm})$. 
The specimens were overlapped with $30 \mathrm{~mm}$ spacing and welded as shown in Fig. 1. The electrode force was fixed at $6 \mathrm{kN}$ and controlled during experiments. The welding time was applied as 10, 15, 20, 25, and 30 periods (per). Clamping and hold times remained constant as 25 per in all series. The welding current was increased from $6 \mathrm{kA}$ to $14 \mathrm{kA}$ by $0.5 \mathrm{kA}$ increments. Therefore, different welds joint properties were obtained.

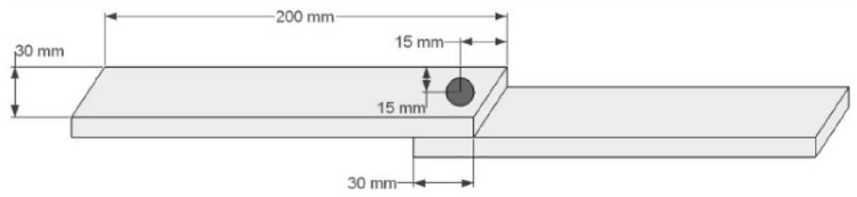

Fig. 1. The dimensions of the specimens.

Nugget diameters $d 1$, nugget heights $d 2$ were measured and also nugget size ratios $d 2 / d 1$ were calculated by means of an optical microscope. Weld nugget geometry is shown in Fig. 2. The effect of welding current on nugget size was investigated by putting obtained results in related diagrams.

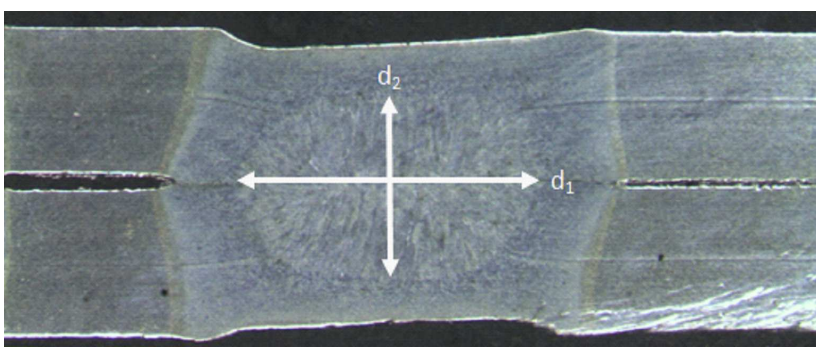

Fig. 2. Weld nugget geometry.

Nugget diameter $d 1$ or nugget height $d 2$ is not enough to explain the effect of welding nugget on quality of joints. Therefore, nugget size ratio $d 2 / d 1$ can be used for this purpose [5].

\section{Results and discussion}

In low welding time application, small weld nugget diameters were obtained due to low heat application to welding zone. As a result, break type was observed as separation as shown in Fig. 3. However, the nugget diameter increases with increasing welding time. This situation is depicted in Fig. 4. Therefore, break type was observed as knotting, as shown in Fig. 5.

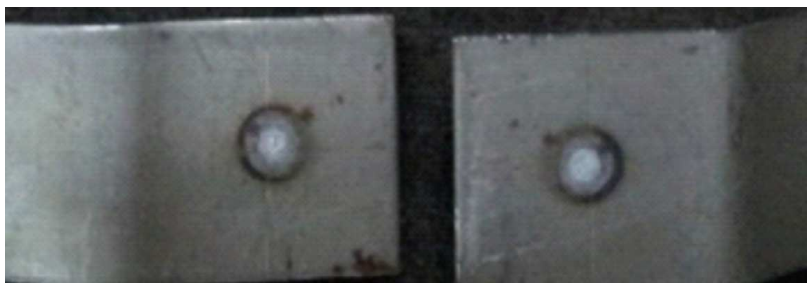

Fig. 3. Separation failure observed in weld nuggets.
In high welding time application, cross-section area decreases. Electrodes react to work piece due to excessive heating of them which cannot be compensated by cooling water. In addition, weld nugget spurts out between two sheets resulting in the decrease in nugget diameter as shown in Fig. 6. At the same time, an over-coloured, retained structure with deep electrode marks and deformations was determined in weld zone.

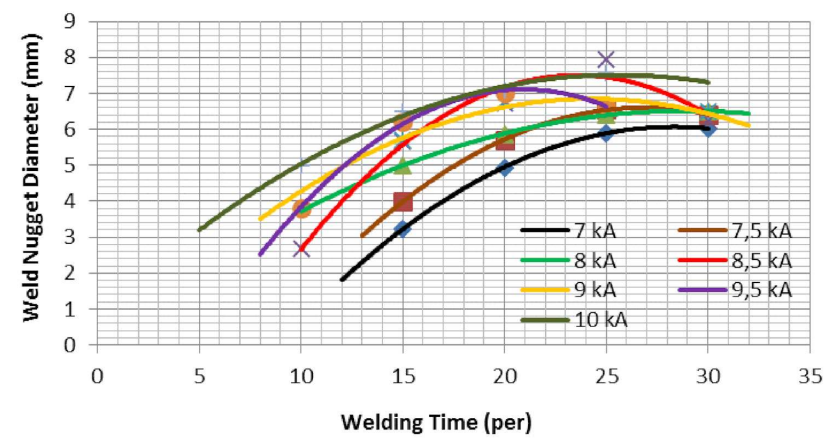

Fig. 4. The effect of welding time on nugget diameter.

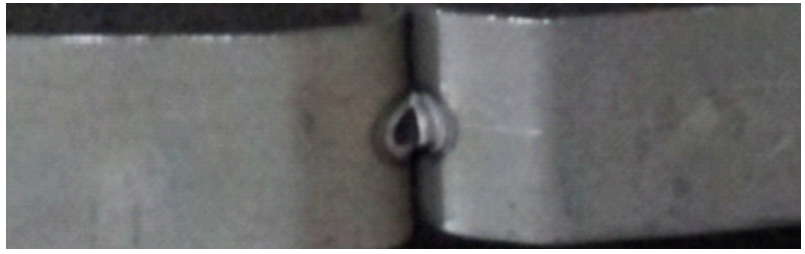

Fig. 5. Knotting failure observed in weld nuggets.

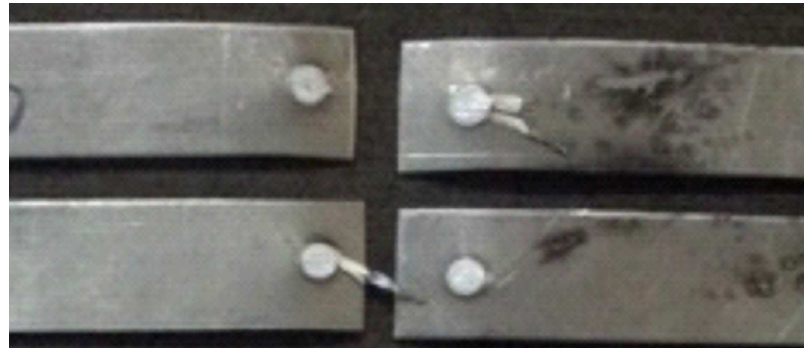

Fig. 6. Spurt out failure observed in weld nuggets.

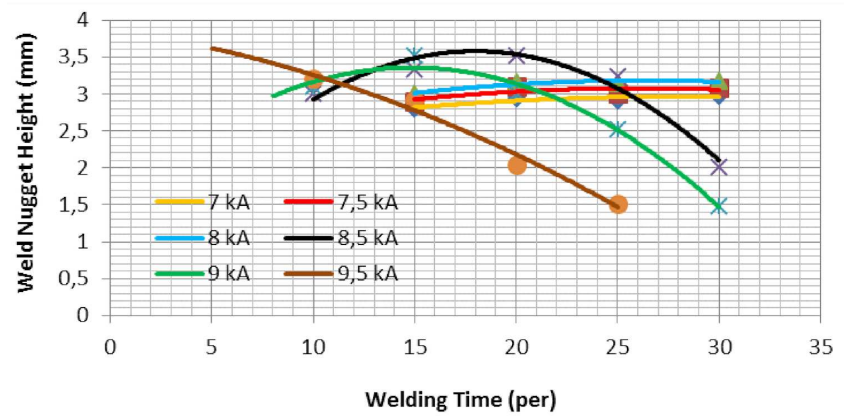

Fig. 7. The effect of welding time on nugget height. 
Despite the increasing welding time as shown in Fig. 7, nugget height is decreases. Weld heat input due to the increase of welding time is increased. Therefore, molten metal quantity is increased. Then, nugget expulsion emerges due to excessive electrode indentation. Therefore, nugget height decreases.

The increasing welding time as shown in Fig. 8, nugget size ratio is increased to a certain value. After that value, it is reduced, because nugget height due to increased electrode indentation is reduced.

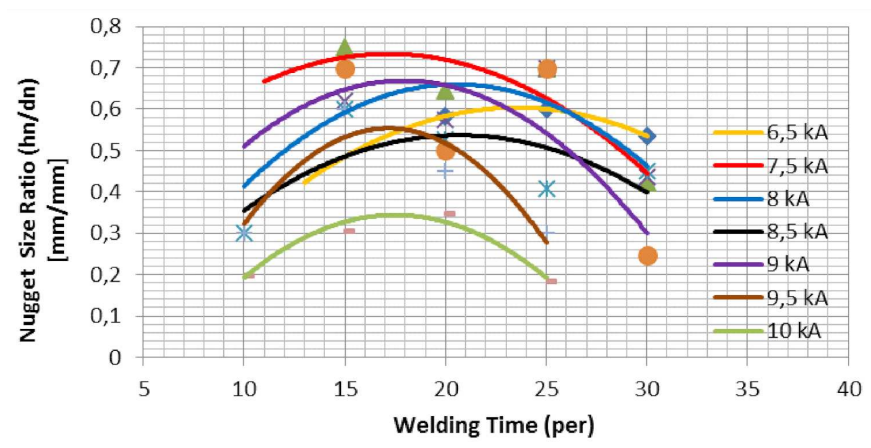

Fig. 8. The effect of welding time on nugget size ratios.

\section{Conclusion}

As a result of the work performed at $6 \mathrm{kN}$ electrode force, the obtained results are given below:

In low welding time, small weld nugget diameter were obtained due to low heat application to welding zone. As a result, break type was observed as separation.

In high welding time, cross-section area decreases. Weld nugget spurts out between two sheets resulting in the decrease in nugget diameter.

When the high surface quality is prior to strength, $9 \mathrm{kA}$ in 20 per or $8.5 \mathrm{kA}$ in 25 per are enough. Since the depth of electrode indentation into material is not exceeded, the $30 \%$ of sheet thickness limit accepted for a good surface quality.

\section{References}

[1] Z. Han, Ph.D. Thesis, Illinois University, 1992.

[2] A. Hasanbasoglu, R. Kacar, Mater. Des. 28, 1794 (2007).

[3] A.M. Al-Mukhtar, Q. Doos, Adv. Mater. Sci. Eng. 2013, 1 (2013).

[4] M.I. Khan, Ph.D. Thesis, University of Waterloo, 2007.

[5] M. Vural, Ph.D. Thesis, Istanbul Technical University, 1992 